\title{
Geographic tongue and psoriasis: clinical, histopathological, immunohistochemical and genetic correlation - a literature review*
}

\author{
Bruna Lavinas Sayed Picciani ${ }^{1}$ \\ Thays Teixeira-Souza ${ }^{1}$ \\ Heron Fernando de Sousa Gonzaga ${ }^{2}$ \\ Alexandre Carlos Gripp ${ }^{3}$ \\ Sueli Carneiro ${ }^{3}$
}

\author{
Tábata Alves Domingos ${ }^{1}$ \\ Vanessa de Carla Batista dos Santos ${ }^{1}$ \\ Juliana Cardoso-Oliveira ${ }^{3}$ \\ Eliane Pedra Dias ${ }^{1}$
}

DOI: http://dx.doi.org/10.1590/abd1806-4841.20164288

\begin{abstract}
Geographic tongue is a chronic, inflammatory, and immune-mediated oral lesion of unknown etiology. It is characterized by serpiginous white areas around the atrophic mucosa, which alternation between activity, remission and reactivation at various locations gave the names benign migratory glossitis and wandering rash of the tongue. Psoriasis is a chronic inflammatory disease with frequent cutaneous involvement and an immunogenetic basis of great importance in clinical practice. The association between geographic tongue and psoriasis has been demonstrated in various studies, based on observation of its fundamental lesions, microscopic similarity between the two conditions and the presence of a common genetic marker, human leukocyte antigen (HLA) HLA-C*06. The difficulty however in accepting the diagnosis of geographic tongue as oral psoriasis is the fact that not all patients with geographic tongue present psoriasis. Some authors believe that the prevalence of geographic tongue would be much greater if psoriatic patients underwent thorough oral examination. This study aimed to develop a literature review performed between 1980 and 2014, in which consultation of theses, dissertations and selected scientific articles were conducted through search in Scielo and Bireme databases, from Medline and Lilacs sources, relating the common characteristics between geographic tongue and psoriasis. We observed that the frequency of oral lesions is relatively common, but to establish a correct diagnosis of oral psoriasis, immunohistochemical and genetic histopathological analyzes are necessary, thus highlighting the importance of oral examination in psoriatic patients and cutaneous examination in patients with geographic tongue.
\end{abstract}

Keywords: Arthritis, psoriatic; Glossitis, benign migratory; HLA antigens; Immunohistochemistry; Psoriasis

Received on 06.12.2014.

Approved by the Advisory Board and accepted for publication on 26.05.2015.

* Study performed at dermatology clinic of Hospital Universitário Pedro Ernesto - Universidade do Estado do Rio de Janeiro (HUPE-UERJ). Post-graduate program in pathology - Universidade Federal Fluminense (UFF) and Histocompatibility and cryopreservation laboratory - Universidade do Estado do Rio de Janeiro (HLA-UERJ) - Rio de Janeiro (RJ), Brazil.

Financial support: none.

Conflict of interest: none.

Universidade Federal Fluminense (UFF) - Niterói (RJ), Brazil.

Universidade de Marília (Unimar) - Marília (SP), Brazil.

Universidade do Estado do Rio de Janeiro (UERJ) - Rio de Janeiro (RJ), Brazil.

C2016 by Anais Brasileiros de Dermatologia 


\section{INTRODUCTION}

First described by Reiter in 1831, the geographic tongue (GT) is a chronic, inflammatory oral lesion, immunologically mediated and with unknown etiology. ${ }^{1-5}$ It affects between $0.6 \%$ and $4.8 \%$ of the world population, occurring more often in children, with a slight preference for females, and with its frequency reducing with age..$^{5-7}$ It is characterized by serpiginous white areas around the depapillated mucosa, whose rotation among activity, remission and reactivation in diverse locations originated the denominations benign migratory glossitis and wandering rash of the tongue. ${ }^{8}$

The white border consists of filiform papillae in regeneration and of a mixture of keratin and neutrophils, while erythematous area results from the loss of these papillae. Lesions tend to change location, pattern and size over time, affecting mainly the back and side edges of the tongue. ${ }^{1-3}$ This migration is evidenced by epithelial desquamation in one location and a simultaneous proliferation in another, with periods of exacerbation and remission. ${ }^{3}$ In most cases it is asymptomatic. However, some patients may report pain or burning sensation, especially during ingestion of spicy or acidic foods. ${ }^{3,4}$,

Psoriasis is a skin-articular disease, inflammatory, chronic, common, with genetic and immunological basis, and with great importance in clinical practice. ${ }^{10,11}$ Psoriasis occurs in approximately $1-3 \%$ of the world population, affecting white individuals of both sexes. Clinically, psoriasis is divided into vulgaris, guttate, inverse, psoriatic arthritis, palmoplantar, pustular and erythrodermic, with common features such as erythema, desquamation and elevation. ${ }^{11-13}$ Its etiology is unknown, but it is known that there is a defect in the normal cycle of epidermal development, with a disorder in the proliferation and differentiation of keratinocytes associated with inflammatory and vascular changes, with a leukocyte infiltrate composed of activated T-lymphocytes, neutrophils, dendrocytes and mast cells. The disease can be localized or generalized, affecting almost all the skin with an unpredictable course..$^{10,14,15}$

Studies show that geographic tongue is the oral manifestation more commonly associated with psoriatic disease. These studies are based on observation of its fundamental lesions, on microscopic similarity between the two conditions and on observation of the presence of a common genetic marker, the human leukocyte antigen (HLA) HLA-Cw6. ${ }^{16-19}$ The difficulty in accepting the diagnosis of geographic tongue as oral psoriasis resides in the fact that some nonpsoriatic patients present geographic tongue. ${ }^{20}$ Some authors believe that the prevalence of oral lesions would be much higher if the psoriatic patients underwent thorough oral examination. ${ }^{16}$ Also, there are few controlled studies with histological and genetic tests on geographic tongue and its relation to psoriasis. ${ }^{17,20}$

To solve the controversy, the aim of this study was to review the literature, describing the relation between psoriasis and geographic tongue.

\section{COLLECTION METHOD}

This study consists of a literature review, conducted between 1980 and 2014, in which was performed a consultation of thesis, dissertations and scientific articles, selected through search in the Scielo and Bireme databases, from Medline and Lilacs sources. The search in the databases was conducted using the keywords geo- graphic tongue, benign migratory glossitis, oral psoriasis and psoriasis. We selected 63 studies in English or Portuguese that addressed the content of interest for the construction of each topic of this article.

\section{Geographic tongue association to other diseases and etiologic factors}

Several associations have been described between geographic tongue and diabetes mellitus, Reiter's syndrome, Down syndrome, pregnancy, psychological factors, family history and consumption of some medications, such as oral contraceptive pills and lithium carbonate. ${ }^{1,3}$ However, the disease to which it presents a higher association is psoriasis. ${ }^{21}$

Allergy has also been suggested as an etiologic factor in geographic tongue. ${ }^{1,6}$ A relation between geographic tongue and asthma, eczema, hay fever, elevated immunoglobulin E (IgE) serum level and atopic patients was reported. It is a common lesion in patients that present recurrent acute inflammatory conditions. Psychosomatic factors, which probably contribute to both geographic tongue and atopy, may explain the high prevalence in atopic patients. ${ }^{6}$

Some studies have shown a relation between geographic tongue and fissured tongue (FT), which manifests itself as grooves on the back of the tongue. ${ }^{3,6,22}$ It has an incidence between $5 \%$ and $10 \%$ of the world population, manifesting variably in number and depth of the bumps. ${ }^{23}$ Usually, the lesions are irreversible, the prevalence increases with age and it probably results from a long term glossitis. ${ }^{3,24}$ Familial occurrence of fissured and geographic tongue in parents and siblings of patients with one or both of these conditions has been studied, suggesting that these lesions have hereditary features of polygenic transmission. ${ }^{22}$

Some bacterial and fungal infections were related to geographic tongue due to the nature of the inflammatory lesion. However, no particular micro-organism was consistently found in association with the disease. ${ }^{1}$

Generalized glossitis with papillary atrophy related to dietary deficiencies of iron and B vitamins led to the suspicion of a possible association between geographic tongue and nutritional deficiencies. There is the possibility of this type of glossitis, related to nutritional deficiencies, to be sometimes confused with geographic tongue, especially when the apex and the side edges of the tongue are affected. ${ }^{25}$

Psychosomatic factors are mentioned as possible etiological factors due to the clinical observation that outbreak or exacerbation of lesions are usually accompanied by a stressful event, as occurs in psoriasis. ${ }^{26}$

Gonzaga et al conducted a study with 129 patients with psoriasis, 399 patients with geographic tongue and 5,472 healthy individuals, evaluating the association of these conditions to alcohol, tobacco and stress. The authors found a high prevalence of alcohol consumption in psoriatic patients and a strong relation between psoriasis and GT with psychosomatic factors. Furthermore, the three related factors were four times more frequently in psoriatic patients. They concluded that interactions between environmental factors and psoriasis are different from the interactions that occur with GT and suggested that these differences may be responsible for different types of manifestations, considering they as the same disease. ${ }^{27}$ 
Regarding tobacco use, some studies report that GT is less common in smokers, due to changes that occur in their oral epitheli$u m$, such as increased keratinization and decreased TNF- $\alpha$, IL- 1 and IL-6 production by macrophages (activation of nicotinic receptors in these cells). However, in psoriasis it is observed that tobacco use is greater than in individuals without this condition., ${ }^{4,11,27}$

\section{PREVALENCE OF GEOGRAPHIC TONGUE IN PSORIASIS AND PSORIATIC ARTHRITIS}

Oral manifestations of psoriatic disease can be divided into two types: the first involves change in mucosa histologically similar to psoriasis, parallel to skin lesions. The other type is more common and is constituted by nonspecific lesions, such as fissured tongue and geographic tongue (Figure 1).28

Geographic tongue is the most common oral lesions in psoriasis, with or without arthritis, presenting high prevalence in these patients, as well relation to the severity of the disease, leading some authors to consider the combination of these conditions. ${ }^{18,21,28}$

Approximately $10 \%$ of patients with psoriasis present geographic tongue. ${ }^{17}$ Generalized pustular psoriasis is most commonly related to geographic tongue. ${ }^{29}$ The presence of geographic tongue in a normal patient indicates an increased likelihood of developing generalized pustular psoriasis. ${ }^{29}$

Fissured tongue is the oral condition most often associated with geographic tongue and is also increased in psoriasis. In skin psoriasis, most lesions are transient, but some lesions may exhibit a more permanent course. Likewise, geographic tongue could be a more transient expression. Moreover, fissured tongue would be a late and permanent expression of oral psoriasis. However, no genetic marker common to the three conditions was determined so far. ${ }^{22}$

Studies show prevalence of fissured tongue ranging from $9.8 \%$ to $47.5 \%$ and of geographic tongue between $5.6 \%$ and $18.1 \%$ (Table 1). ${ }^{17,21,29-33}$

Daneshpazhooh et al evaluated 200 patients with psoriasis and 200 patients without psoriasis. They found fissured tongue in $33 \%$ and geographic tongue in $14 \%$ of patients with psoriasis; in the control group, they found fissured tongue in $9.5 \%$ and geographic tongue in $6 \%$ of patients. ${ }^{29}$ The authors reported that $32 \%$ of patients with psoriasis and GT had severe psoriasis, relating this lesion to disease severity.

Zargari conducted a prospective study on the prevalence of tongue lesions in psoriatic patients. All patients with psoriasis being assisted in a dermatology clinic for five years were evaluated. The author observed that there were 306 psoriatic patients, and $47(15 \%)$ presented tongue lesions, 25 (8\%) fissured tongue, 17 (6\%) geographic tongue and $5(2 \%)$ the two lesions concomitantly. Geographic tongue was observed in $7 \%$ of patients with early psoriasis and in $1 \%$ of patients with late psoriasis. The author concluded that the incidence of geographic tongue in early psoriasis may be an indicator of disease severity. ${ }^{30}$

Hernandes-Pérez et al examined 80 psoriatic patients and 127 healthy individuals, finding fissured tongue in $47 \%$ of patients with psoriasis and in $20 \%$ of controls. Geographic tongue was present in $12 \%$ and $5 \%$ of patients in psoriasis and control groups, re-
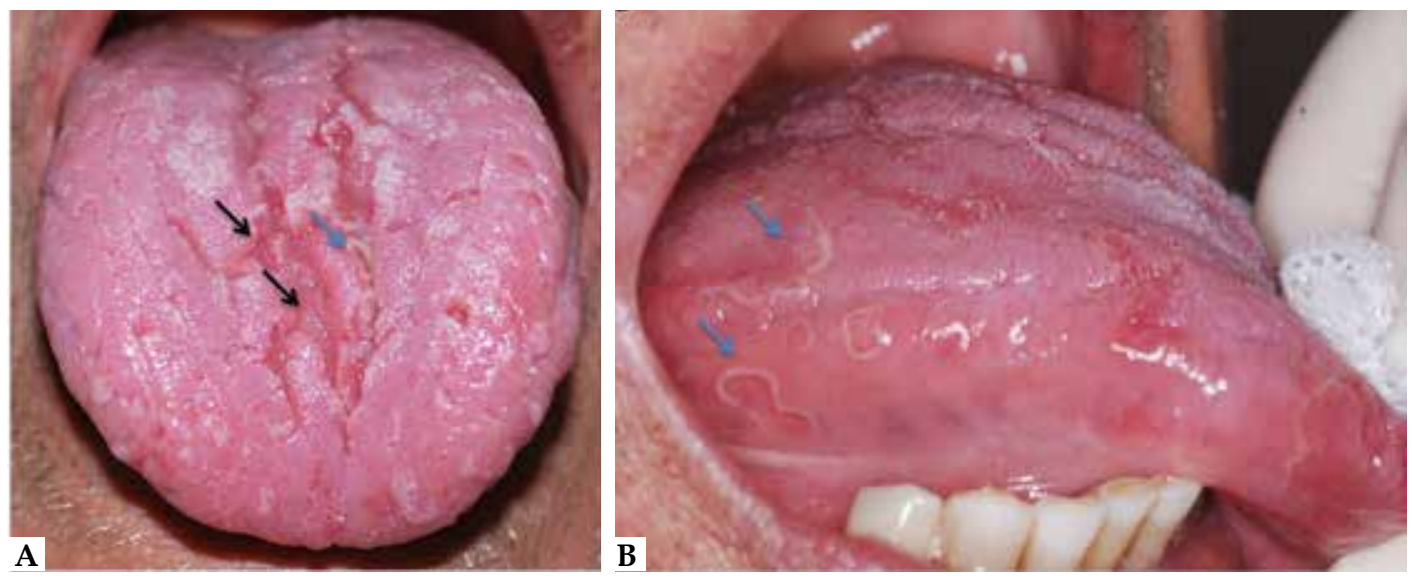

Figure 1: $A$ and $B$ Clinical association of fissured tongue (black arrow) and geographic tongue (blue arrow) in psoriatic patient

TABLE 1: Geographic tongue and fissured tongue prevalence in psoriatic patients and control subjects

\begin{tabular}{|c|c|c|c|c|c|c|}
\hline \multirow[t]{2}{*}{ References } & \multicolumn{2}{|l|}{ Total (n) } & \multicolumn{2}{|c|}{ Geographic tongue (\%) } & \multicolumn{2}{|c|}{ Fissured tongue (\%) } \\
\hline & Psoriasis & Control & Psoriasis & Control & Psoriasis & Control \\
\hline Daneshpazhooh et al. (2004) ${ }^{29}$ & 200 & 200 & 14 & 6 & 33 & 9.5 \\
\hline Zargari $(2006)^{30}$ & 306 & $\mathrm{~N}$ & 7.2 & $\mathrm{~N}$ & 9.8 & $\mathrm{~N}$ \\
\hline Hernández-Pérez et al. $(2008)^{21}$ & 80 & 127 & 12.5 & 4.7 & 47.5 & 20.4 \\
\hline Costa et al. $(2009)^{31}$ & 166 & 166 & 18.1 & 4.2 & 34.3 & 16.2 \\
\hline Tomb et al. $(2010)^{32}$ & 400 & 1000 & 7.7 & 1 & 33.2 & 9.9 \\
\hline Picciani et al. (2011) $)^{17}$ & 203 & $\mathrm{~N}$ & 12.1 & $\mathrm{~N}$ & 34.4 & $\mathrm{~N}$ \\
\hline Singh et al. $(2013)^{33}$ & 600 & 800 & 5.6 & 0.8 & 45.3 & 40 \\
\hline
\end{tabular}

$\mathrm{N}$ - It does not present control and analysis of the presence of geographic tongue or fissured tongue 
spectively. The authors concluded that these lesions can be a predecessor or a marker of psoriasis severity. ${ }^{21}$

Costa et al evaluated the oral mucosa of 166 psoriatic patients and 166 healthy subjects demonstrating a significant association between fissured tongue and geographic tongue when psoriatic patients were compared with the control group. The authors concluded that GT and FT are the only oral lesions associated with psoriasis, but are not exclusive of this disease. ${ }^{31}$

Tomb et al showed an association between GT/FT and psoriasis, highlighting the increase of these lesions in pustular psoriasis. ${ }^{32}$

Picciani et al showed a high level of GT and FT in patients with psoriatic disease, highlighting the higher prevalence of GT in early psoriasis and of FT in late psoriasis. ${ }^{17}$

Singh et al evaluated 600 psoriatic patients and concluded that the geographic tongue is increased in psoriasis and related to disease severity. ${ }^{33}$ The authors also showed that $79 \%$ of psoriatic patients with GT were male. This data differs from patients with GT without psoriasis who are usually female, and hormonal factors are identified as triggers or intensifiers of the lesion. ${ }^{5}$

Picciani evaluated in 284 psoriatic patients the relation between severity and presence of geographic tongue through PASI, demonstrating that severe psoriasis occurred in $25 \%$ of patients without GT and in $58 \%$ of patients with GT. The author concluded that GT may be considered a marker of severity of psoriasis. ${ }^{34}$

Some authors reported a significant increase of GT in patients with early psoriasis, which reinforces the Picciani theory that GT is directly related to the severity of the skin disease. ${ }^{17,30,34}$

Facial involvement associated to the presence of geographic tongue and psoriatic arthritis is found in cases of severe psoriasis, being directly related to disease severity.35 Keshavarz et al demonstrated in a study with 138 psoriatic patients that $55 \%$ of cases presented facial involvement, $13 \%$ articular involvement, and 24\% GT. The authors concluded that there is a significant relation between facial lesion and increased severity. ${ }^{35}$ In addition to geographic tongue, the involvement of the temporomandibular joint (TMJ) may occur in patients with psoriatic arthritis (PA), particularly in patients with HLA-B27, but this is still a little reported fact, with only 19 articles and 43 cases found in the literature review. ${ }^{28,36}$ The involvement of this joint can cause pain, swelling and limitation of movement. This involvement is more prevalent in the 4 th decade of life and occurs between $31 \%$ and $63 \%$ of cases of PA. ${ }^{28,36}$ Approximately $30 \%$ of patients examined in Picciani study presented some joint involvement without affecting the TMJ. ${ }^{34}$ A multidisciplinary approach, involving dermatologists, rheumatologists and dentists, is the safest option for the diagnosis and treatment of these patients. The low prevalence of TMJ involvement in PA may be related to the lack of a thorough examination of the TMJ in psoriatic patients, which consequently causes few clinical and epidemiological reports in the literature. ${ }^{36}$

Gonzaga \& Consolaro conducted a study with 118 patients with psoriasis and 88 patients with geographic tongue, and observed a reversal in the age groups of patients, in which geographic tongue occurred at earlier ages, suggesting that this is a predecessor manifestation of the skin condition. In this study, the similarity between psoriasis and geographic tongue from the fun- damental lesions and symptoms was also identified.$^{37}$ In geographic tongue, the erythematous and depapillated lesions correspond to skin peeling; and, just as in psoriasis, they follow a chronic course presenting periods of remission and exacerbation, which can occur in days, weeks or months. ${ }^{16,37}$ The process of chewing and speaking is a factor of constant trauma to the tongue, which could correspond to Koebner phenomenon, stimulating the emergence of geographic tongue ${ }^{37}$ Most patients presenting symptoms report burning sensation in skin lesions and in geographic tongue. ${ }^{37}$ The authors conclude that the prevalence of specific oral lesions of psoriasis would be much higher than the one reported due to the fact that, as a rule, patients are not subjected to a full and thorough oral examination, which would bring reliable results to help resolve this divergence. ${ }^{37}$

\section{HISTOPATHOLOGIC AND IMMUNOGENETIC SIMILARI- TIES BETWEEN GEOGRAPHIC TONGUE AND PSORIASIS}

Geographic tongue may present histopathology and immunogenetic patterns similar to psoriasis, leading some authors to consider the association between these diseases (Figure 2). ${ }^{8,18,19,32}$

\section{Histopathologic similarities}

Microscopic findings of psoriasis are very characteristic: regular increase of the spinous layer with thickening of the lower portions; thickening and swelling of papillae; suprapapillary hypotrophy with occasional presence of a small spongiform pustule; absence of granular layer; parakeratosis; presence of Munro's microabscess; and inflammatory cell infiltration, particularly T-lymphocytes, macrophages and neutrophils, in the dermis and submucosa. These microscopic findings are also seen in the geographic tongue, highlighting the histopathological similarity between the two diseases (Figure 3)..$^{38-42}$ However, in geographic tongue and psoriasis, histopathologic characteristics may vary according to the clinical stage of the lesion and the biopsied area. ${ }^{18}$

Femiano compared two groups, each consisting of 20 patients. One group was composed of patients with skin psoriasis and lesions in the oral mucosa similar to geographic tongue. The other group consisted of individuals affected only by geographic tongue. Biopsies were performed in the oral lesions. In the first group, all analyzes were histologically compatible with psoriasis. In the second, these characteristics were observed in $80 \%$ of subjects. Thus, the author considered the geographic tongue as an oral manifestation of psoriasis, but he questioned the possibility of a type of geographic tongue not associated with psoriasis. ${ }^{18}$

In geographic tongue, the white area of lesion presents subepithelial infiltrates with predominance of neutrophils, and abundant exocytosis of these cells, forming microabscesses and, in some cases, pustules. The erythematous area of the lesion shows mononuclear subepithelial infiltrate, suprapapillary hypertrophy and vascular ectasia.5 In a study via electron microscopy, it was observed that the erythematous area presents loss of filiform papillae and the white region shows necrotic cells that are flaking. ${ }^{5}$

Picciani evaluated and compared the histopathologic features of GT lesions in patients with and without psoriasis, also comparing skin lesions among these patients. It was demonstrated that most of the classical histopathologic features of psoriasis 
was observed in all cases, such as parakeratosis, acanthosis, suprapapillary epithelial atrophy, spongiosis, hyperplasia of basal layer, ridges fusion, exocytosis, and presence of superficial and papillary inflammatory infiltrate. However, in the peripheral area of GT lesions, remarkable differences between the groups were found, in which oral lesions of psoriatic patients demonstrated hyperplastic, inflammatory and vascular changes from the periphery. The study of these aspects in the periphery of the lesion, perhaps, could help to distinguish between geographic tongue and true oral psoriasis. ${ }^{34}$
Munro's microabscess (collections of neutrophils in the corneal layer) is present in over $75 \%$ of cases of psoriasis. Pustule of Kogoj, which is also a collection of neutrophils, but in the spinous layer, is more present in cases of pustular psoriasis. ${ }^{38}$ Neutrophils are recruited by interleukin, ${ }^{8}$ which is synthesized by CD4+ T-cells; then migrate through the epidermis, forming the collections of neutrophils. ${ }^{43}$ Picciani found a high prevalence of pustule of Kogoj in GT lesions, reinforcing the theory that geographic tongue represents a pustular manifestation of psoriasis. ${ }^{29,34}$ Evaluate oral and cutane-
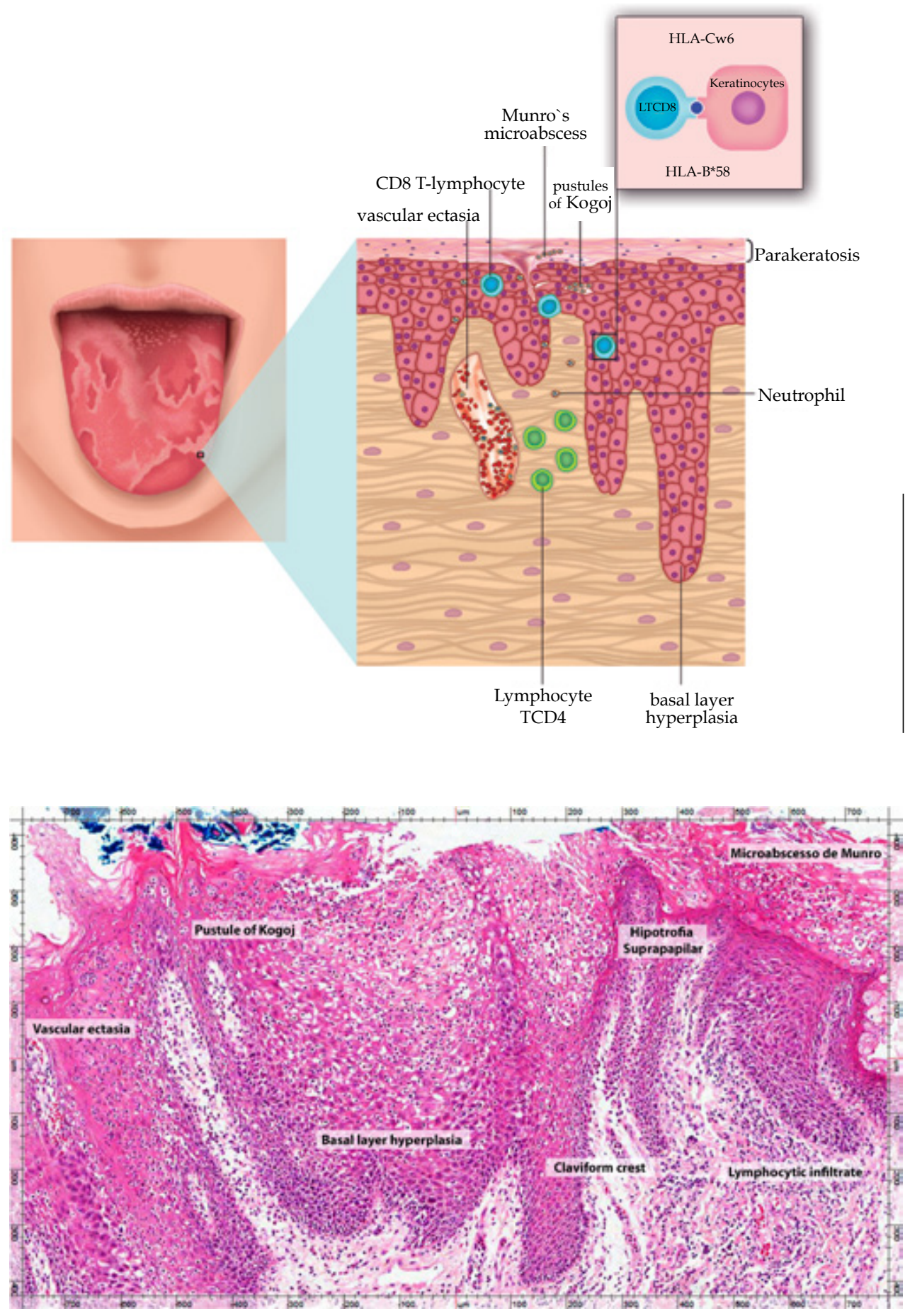

FIGURE 2:

Major clinical, histopathological and immunogenetic features found in geographic tongue, showing similarity between GT and psoriasis. Highlighted image of the interaction found in geographic tongue among the CD8 T-lymphocytes, HLA-Cw6 and -B58 and keratinocytes
FIGURE 3:

Main histopathological aspects of geographic tongue 
ous lesions of patients with pustular psoriatic patients could help better understand this relation.

Many authors believe that, to establish the diagnosis of oral psoriasis, is necessary the presence of skin lesions with parallel course to oral lesions. ${ }^{20,28}$ Histopathological findings associated with the parallel improvement of skin lesions of psoriasis and tongue lesions with systemic retinoid treatment support the hypothesis that the geographic tongue is a form of psoriasis. ${ }^{40}$

To investigate the relation of these conditions, it is necessary the conduction of incisional biopsy of geographic tongue, covering the three areas of the lesion: the margin, the white line and the erythematous region. However, despite the geographic tongue is no longer considered a development change, the diagnosis is mainly based on clinical examination, with only two histopathology studies found, which impacts negatively the understanding of the pathogenesis of GT and its relation with psoriasis.

\section{Immunogenetic similarities}

In psoriasis, the inflammatory infiltrate is predominantly mononuclear, consisting mainly of T-cells, CD4 + in the dermis and CD8 + in the epidermis. T-lymphocytes play a major role in epidermal and vascular changes of psoriasis, being responsible for the production of several cytokines and chemokines. Macrophages and Langerhans cells and are main cells presenting antigens involved in psoriasis. Activated macrophages release cytokines and stimulate keratinocytes to produce cytokines such as TNF- $\alpha .^{41}$ Langerhans cells constitute about $25 \%$ of the inflammatory cells of psoriasis, being more abundant in the dermis. The infiltrate in psoriatic oral lesions also consists of macrophages and T-cells, especially CD4, and the few immunohistochemical studies on geographic tongue show a similar abundance of CD4+.8,16,34,42

An immunohistochemical study conducted in nonpsoriatic patients with geographic tongue, with reports of family history of psoriasis, showed similar cellular distribution between these conditions. Dilated and tortuous capillaries found in the dermis layer are marked with anti-CD31 antibody with the same intensity of psoriatic lesions. The nuclear proliferation, evidenced as a Ki-67 marker, abundant in psoriasis, is seen similarly in the geographic tongue, in which an increase in the proliferation of basal and parabasal cells is observed. The diagnosis of oral psoriasis was not established due to the lack of cutaneous manifestations. ${ }^{8}$

There are few studies evaluating the inflammatory response in geographic tongue. Espelid et al performed an immunohistochemical study in GT lesions and CD3, CD4, CD8, CD22, CD11c and HLA-DR antibodies, showing that subepithelial inflammatory infiltrate is predominantly mononuclear, with CD4+ T-lymphocytes, followed by the presence of macrophages. ${ }^{42}$ Ulmansky et al also showed that the subepithelial inflammatory infiltrate of GT has abundant presence of CD4+ T-lymphocytes. ${ }^{16}$ These studies concluded that there is a connection between GT and psoriasis. ${ }^{16,42}$ Picciani (2014) conducted an investigation of the inflammatory response in patients with geographic tongue, with and without psoriasis, using CD1a, CD3, CD4, CD8, CD20 and CD68 antibodies. The study showed that oral and cutaneous lesions present similar pattern of qualitative and quantitative marking, regardless of the antibody used. Oral and skin lesions of psoriatic patients revealed a higher prevalence of TCD3, TCD4 and TCD8 cells (Figure 4). ${ }^{34}$ Cabrijan et al compared the expression of CD4+ and CD8+ T-lymphocytes in 50 cases of psoriasis vulgaris and 50 cases of normal skin, and found a significant increase of these lymphocytes in psoriasis. ${ }^{43}$ Vissers et al compared the expression of CD4+ and CD8+ T-lymphocytes in the center, within and on the edge of psoriatic plaques, and found an increased number of CD4+ T-cells in the dermis of all areas of the lesion. ${ }^{44}$ In the epidermis, they observed a higher expression of CD8+ T-cells in the center and the inner edge of the lesion. Thus, they concluded that CD8 cells are important in the initial phase of psoriasis. ${ }^{44}$ In Picciani study, the analysis by area of oral lesions showed that in the peripheral area there is an increase of T-cells, particularly $\mathrm{CD} 4+$, in geographic tongue of nonpsoriatic patients, and of $\mathrm{CD} 8+$ in geographic tongue of psoriatic patients. This reinforces the importance of using the assessment of lesions margins of geographic tongue to define the true oral psoriasis. ${ }^{34}$ Facing psoriasis-like lesions, such as geographic tongue, which cause difficulties in diagnosis, distinguishing the two lesions based on T-cells infiltrate immunophenotyping can be a useful tool. The difference in the quantity and distribution pattern of CD4+ and CD8+ T-cells may assist in diagnostic decision, especially in cases presenting very similar histopathologic features. ${ }^{45}$

Despite the unknown etiology, some authors suggest that there is a genetic basis between psoriasis and geographic tongue. One of the most well-known genetic factors of susceptibility for psoriasis is the human leukocyte antigen (HLA), located on the short arm of chromosome 6.46 The HLA system is divided into three regions: class I, class II and class III, according to the structure and function of its genes. ${ }^{47}$ In the literature, there are few studies on genetic analysis in geographic tongue, and only four studies on this association were found, demonstrating relation with the HLA-B13, -B15, -CW6, DR5 and DRW6 antigens. ${ }^{19,48-50}$

In 1987, a study was conducted to evaluate the association between GT and diabetes mellitus, in which the presence of an HLA allele between these conditions was demonstrated. In HLA typing, an increase in the HLA B-15 frequency, now subdivided into HLABw62 and HLA-Bw63, was found in the diabetes group with GT and in patients only with diabetes, suggesting a weak association between endocrine dysfunction and oral lesion. ${ }^{48}$

Subsequently, in 1993, a serologic study was conducted with 50 participants with GT and 380 healthy individuals, in which HLA relation with this lesion pathogenesis was examined. It was observed an increase in HLA-B51 antigen expression in control subjects and increased prevalence of HLA-DR5 and -DR6 in the GT group. ${ }^{50}$

Gonzaga et al found a strong association among HLA$\mathrm{Cw}^{*} 06$, psoriasis and geographic tongue, concluding that some cases of geographic tongue may represent an authentic manifestation of psoriasis. ${ }^{19} \mathrm{HLA}-\mathrm{CW}^{*} 06$ is the main allele of susceptibility to psoriasis, with or without arthritis, regardless of ethnic group. ${ }^{51}$ The explanation for this association is a recognition of antigen specific by CD8+ T-cells resulting in stimulation of keratinocytes proliferation. These cells, in response to the binding of antigens with HLA-C*06: 02 and keratinocytes, act as the main effector cells in the maintenance of pathogenic process. ${ }^{52,53}$ 
Gonzaga et al demonstrated a positive association between the HLA-B17 antigen and geographic tongue, and this finding was reinforced by Picciani, which showed for the first time the association between geographic tongue and HLA-B $* 58$ allele, confirming the association between HLA-B ${ }^{*} 57$ allele and psoriasis. ${ }^{19,54}$ The serologic equivalent for these alleles (HLA-B*57 e -B*58) is the HLA-B17 antigen. Possibly this may explain the association between psoriasis and geographic tongue, respectively, with these alleles. ${ }^{54}$

Some studies report that the combination of killer-cell immunoglobulin-like receptor (KIR), which act as ligands of class I HLA molecules and HLA-C alleles, increases the susceptibility to psoriasis. ${ }^{14,55,56}$

Luszczek et al showed in a Polish population the frequency of HLA-C, KIR2DS1 and KIR2DL1. HLA-C*06 was found in 77\% of psoriatic patients and in $17 \%$ of healthy individuals. KIR2DS1 activation gene was significantly higher in the patients, while the KIR2DL1 inhibitory gene was present in most people of both groups. The authors concluded that individuals who have HLA-C*06 and KIR2DS1 activation gene are more susceptible to psoriasis. ${ }^{57} \mathrm{Be}-$ cause HLA molecules regulate the cytotoxic activity of killer-cells, the analysis of KIR genes could contribute to a better understanding of the correlation between geographic tongue and psoriasis.

HLA typing, associated with histopathologic and immunohistochemical analyzes, contributes to the definition of oral psoriasis, and it is essential to make this diagnosis for proper management and treatment of this condition.

Some studies have identified the major class I and II HLA alleles in samples from patients with psoriasis and geographic tongue (Table 2)..$^{19,48,49,58-62}$

A Brazilian study showed that the presence of the polymorphism $+3954 I L-1 B$ is associated with increased risk of geographic tongue development, and it was reported the central role of this interleukin in the pathogenesis of psoriasis. ${ }^{63}$

Alikhani et al analyzed in saliva the TNF- $\alpha$ and IL- 6 concentration in patients with geographic tongue and in healthy subjects and demonstrated a significant increase in both groups of patients, reinforcing the association with psoriasis. ${ }^{26}$

The presence of familial cases and association with HLA genes in both conditions show that there may be common genetic determinants, manifesting only in oral mucosa or presenting a more generalized clinical condition, affecting the skin, while being influenced by certain environmental factors. ${ }^{19,27,37}$

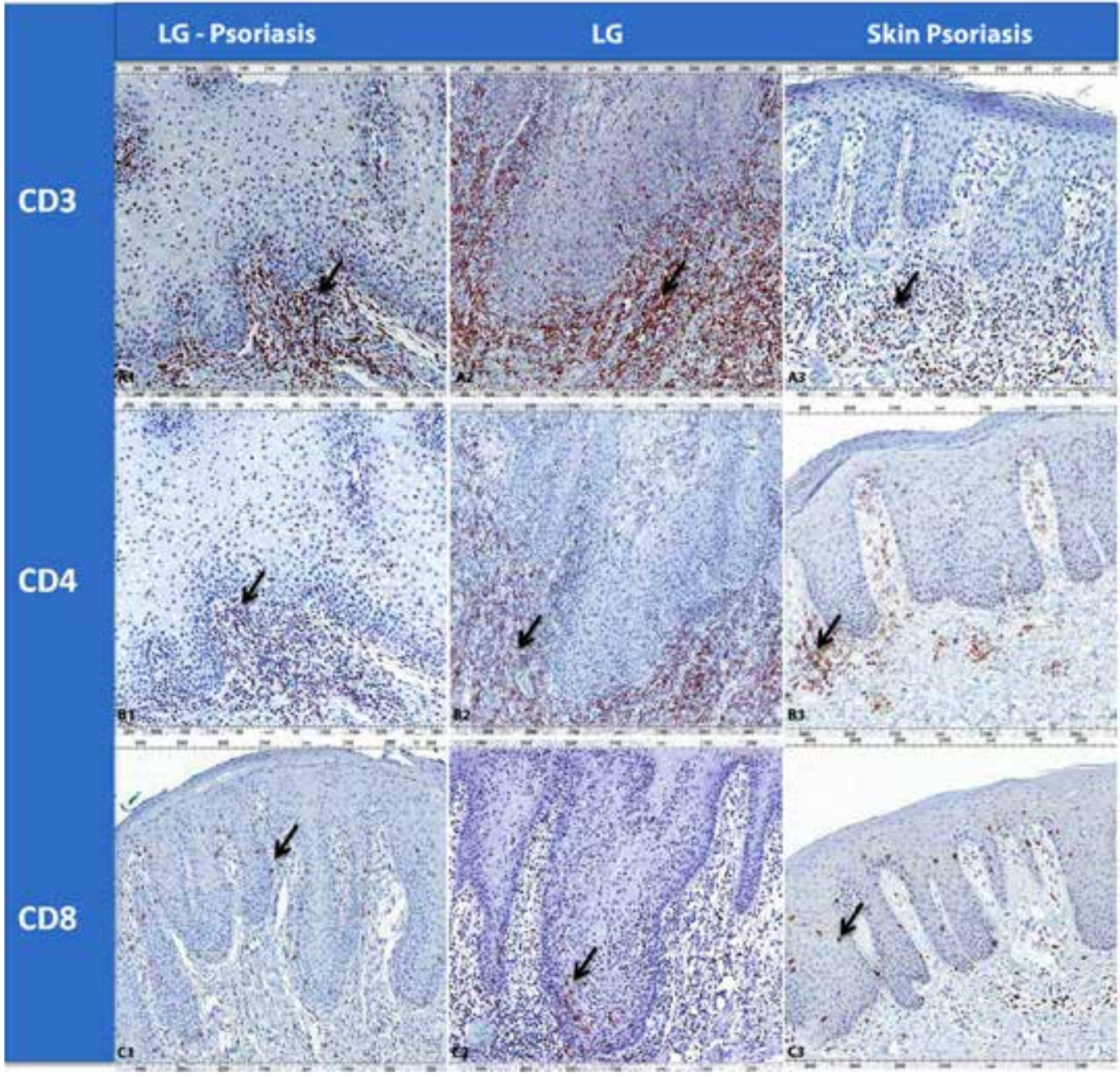

Figure 4:

Immunohistochemical marking aspects of the CD3, CD4 and CD8 cells in patients with geographic tongue with and without psoriatic disease 
TABLE 2: Class I and II HLA often associated with psoriasis vulgaris (PV) and geographic tongue (GT) in population studies (p <0.05)

\begin{tabular}{|c|c|c|c|c|c|c|c|c|c|}
\hline \multirow[t]{2}{*}{ Reference } & \multirow[t]{2}{*}{ Country } & \multicolumn{3}{|c|}{ Sample } & \multicolumn{2}{|c|}{ Class I HLA (OR) } & \multicolumn{2}{|l|}{ Class II HLA (OR) } & \multirow{2}{*}{$\begin{array}{l}\text { HLA } \\
\text { typing } \\
\text { methods }\end{array}$} \\
\hline & & PV & GT & $\mathrm{C}$ & $\overline{\text { PV }}$ & GT & $\overline{\text { PV }}$ & GT & \\
\hline $\begin{array}{l}\text { Marks \& } \\
\text { Taitt }(1980)^{49}\end{array}$ & Australia & - & 95 & & - & B15 & - & - & Serological \\
\hline $\begin{array}{l}\text { Fenerli et al. } \\
(1993)^{50}\end{array}$ & Greece & - & 50 & 380 & - & - & - & $\begin{array}{l}\operatorname{DR} 5(2.2)^{*} \\
\text { DRw6 (3.3)* }\end{array}$ & Serological \\
\hline $\begin{array}{l}\text { Gonzaga et } \\
\text { al. }(1996)^{19}\end{array}$ & Brazil & 22 & 32 & 159 & $\begin{array}{l}\text { Cw6 }(10.0)^{*} \\
\text { B17 }(10.1)^{*} \\
\text { B13 }(6.8)^{*}\end{array}$ & $\begin{array}{l}\text { Cw6 (5.4)* } \\
\text { B13 }(5.7)^{*}\end{array}$ & - & - & Serological \\
\hline $\begin{array}{l}\text { Enerback et } \\
\text { al. }(1997)^{58}\end{array}$ & Sweden & 201 & - & 77 & $\mathrm{CW}^{*} 06$ & - & - & - & Molecular \\
\hline $\begin{array}{l}\text { Kim et al. } \\
(2000)^{59}\end{array}$ & Korea & 84 & - & 98 & $\begin{array}{l}\text { A1 }(17.0)^{*} \\
\text { A30 }(5.5)^{*} \\
\text { B13 }(5.6)^{*} \\
\text { B37 }(30.3)^{*} \\
\text { Cw*0602 }(36.0)^{*}\end{array}$ & - & $\begin{array}{l}\text { DRB1*07 }(5.9)^{*} \\
\text { DRB1*10 }(26.4)^{*} \\
\text { DQA1*02 }(6.2)^{*} \\
\text { DPB1*1701 }(24.6)^{*}\end{array}$ & - & $\begin{array}{l}\text { Serological } \\
\text { Molecular }\end{array}$ \\
\hline $\begin{array}{l}\text { Zhang et al. } \\
(2004)^{60}\end{array}$ & China & 189 & - & 273 & - & - & $\begin{array}{l}\text { DQA1*0104 (2.3) } \\
\text { DQA1*0201 (3.4) }\end{array}$ & - & Molecular \\
\hline $\begin{array}{l}\text { Magalhães et } \\
\text { al. }(2010)^{61}\end{array}$ & Brazil & 69 & - & 70 & $\begin{array}{l}\text { B57 (5.3) } \\
\text { Cw6 (3.9) } \\
\text { Cw12 (3.8) }\end{array}$ & - & DRB1*07 (2.7) & - & Molecular \\
\hline $\begin{array}{l}\text { Shawkatová } \\
\text { et al. }(2013)^{62}\end{array}$ & Slovakia & 147 & - & 194 & $C^{*} 06(3.8)$ & - & $\begin{array}{l}\text { DRB1*07 (2.6) } \\
\text { DQB1*02 (1.1) }\end{array}$ & - & Molecular \\
\hline
\end{tabular}

C - Control group; *RR - Relative Risk; OR - odds ratio; Confidence interval 95\%

\section{DIAGNOSIS}

The diagnosis of geographic tongue is usually based on history and physical examination, except for atypical cases where histopathological examination is necessary. ${ }^{5}$ The lesions are characterized by migratory pattern, circinate aspect and mild pain. ${ }^{8}$

The differential diagnosis includes candidiasis, lichen planus, erythroplasia, lupus erythematosus, trauma and drug reactions. All of these lesions can be discarded after the clinical and histopathological examination. ${ }^{5}$

Due to its variants, diagnosis of psoriasis becomes more complex when compared with geographic tongue, being necessary in some cases a clinicopathological correlation. ${ }^{11}$

\section{TREATMENT}

Because it is a benign and generally asymptomatic lesion, geographic tongue patient does not receive treatment. ${ }^{5}$

Symptomatic treatment is based on the use of oral rinses containing anesthetics, topical corticosteroids, vitamin A, antihistamines and zinc supplements. It is recommended also to avoid contact with irritants and infectious factors, such as dentures and braces, which may exacerbate the situation. The patient should be instructed in relation to diet, avoiding acidic and spicy foods. In addition, patients should be instructed to always maintain good oral hygiene. ${ }^{26}$ Abe et al reported a serious and persistent case of geographic tongue that was treated with systemic use of oral cyclosporine, presenting excellent therapeutical response. ${ }^{40}$ Ishibashi et al showed two symptomatic cases of geographic tongue that used topical tacrolimus with regression of lesions, indicating this medication as a treatment option. ${ }^{1}$

The treatment of psoriasis and psoriatic arthritis requires greater complexity and interaction between different health professionals, depending on the clinical form and severity of the disease. Treatment with photochemotherapy, immunomodulators, immunosuppressants and immunobiologicals alone or in associations is effective for skin, joint and oral disease. ${ }^{10}$

\section{FINAL CONSIDERATIONS}

Geographic tongue is one of the most frequent oral manifestations of psoriatic disease, presenting histopathological, immunohistochemical and genetic similarities with plaque psoriasis. For the correct diagnosis of oral psoriasis, the histopathologic and immunogenetics analysis may be necessary. The extraoral and intraoral thorough examination in psoriatic patients and skin and joint examination in patients with geographic tongue should not be neglected so there is no loss of holistic assessment of the disease. 


\section{REFERENCES}

1. Ishibashi M, Tojo G, Watanabe M, Tamabuchi T, Masu T, Aiba S. Geographic tongue treated with topical tacrolimus. J Dermatol Case Rep. 2010;4:57-9.

2. Zadik Y, Drucker S, Pallmon S. Migratory stomatitis (ectopic geographic tongue) on the floor of the mouth. J Am Acad Dermatol. 2011;65:459-60.

3. Goswami M, Verma A, Verma M. Benign migratory glossitis with fissured tongue. J Indian Soc Pedod Prev Dent. 2012;30:173-5.

4. Honarmand M, Farhad Mollashahi L, Shirzaiy M, Sehhatpour M. Geographic Tongue and Associated Risk Factors among Iranian Dental Patients. Iran J Public Health. 2013;42:215-9.

5. Assimakopoulos D, Patrikakos G, Fotika C, Elisaf M. Benign migratory glossitis or geographic tongue: an enigmatic oral lesion. Am J Med. 2002;113:751-5.

6. Miloğlu 0, Göregen M, Akgül HM, Acemoğlu H. The prevalence and risk factors associated with benign migratory glossitis lesions in 7619 Turkish dental outpatients. Oral Surg Oral Med Oral Pathol Oral Radiol Endod. 2009;107:e29-33.

7. Jainkittivong A, Langlais RP Geographic tongue: clinical characteristics of 188 cases. J Contemp Dent Pract. 2005;6:123-35.

8. Picciani B, Silva-Junior G, Carneiro S, Sampaio AL, Goldemberg DC, Oliveira J, et al. Geographic stomatitis: an oral manifestation of psoriasis? J Dermatol Case Rep. 2012;6:113-6.

9. Zhu JF, Kaminski MJ, Pulitzer DR, Hu J, Thomas HF. Psoriasis: pathophysiology and oral manifestations. Oral Dis. 1996;2:135-44

10. Raut AS, Prabhu RH, Patravale VB. Psoriasis clinical implications and treatment: a review. Crit Rev Ther Drug Carrier Syst. 2013;30:183-216.

11. Chandran V, Raychaudhuri SP. Geoepidemiology and environmental factors of psoriasis and psoriatic arthritis. J Autoimmun. 2010;34:J314-21

12. Johnson MA, Armstrong AW. Clinical and histologic diagnostic guidelines for psoriasis: a critical review. Clin Rev Allergy Immunol. 2013;44:166-72.

13. Ladizinski B, Lee KC, Wilmer E, Alavi A, Mistry N, Sibbald RG. A review of the clinical variants and the management of psoriasis. Adv Skin Wound Care. 2013;26:271-84

14. Bachelez H. Immunopathogenesis of psoriasis: recent insights on the role of adaptive and innate immunity. J Autoimmun. 2005;25:69-73.

15. Chandran V. The genetics of psoriasis and psoriatic arthritis. Clin Rev Allergy Immunol. 2013;44:149-56.

16. Ulmansky M, Michelle R, Azaz B. Oral psoriasis: report of six new cases. J Oral Pathol Med. 1995;24:42-5.

17. Picciani BL, Silva-Junior GO, Michalski-Santos B, Avelleira JC, Azulay DR, Pires FR, et al. Prevalence of oral manifestations in 203 patients with psoriasis. J Eur Acad Dermatol Venereol. 2011;25:1481-3.

18. Femiano F. Geographic tongue (migrant glossitis) and psoriasis. Minerva Stomatol. 2001;50:213-7.

19. Gonzaga HF, Torres EA, Alchorne MM, Gerbase-Delima M. Both psoriasis and benign migratory glossitis are associated with HLA-Cw6. Br J Dermatol. 1996;135:368-70.

20. Migliari DA, Penha SS, Marques MM, Matthews RW. Considerations on the diagnosis of oral psoriasis: a case report. Med Oral. 2004;9:300-3.

21. Hernández-Pérez F1, Jaimes-Aveldañez A, Urquizo-Ruvalcaba Mde L, DíazBarcelot M, Irigoyen-Camacho ME, et al. Prevalence of oral lesions in patients with psoriasis. Med Oral Patol Oral Cir Bucal. 2008;13:E703-8.

22. Gonzaga HF, Marcos EV, Santana FC, Jorge MA, Tomimori J. HLA alleles in Brazilian patients with fissured tongue. J Eur Acad Dermatol Venereol. 2013;27:e166-70.

23. Gonzaga HFS, Costa CAS, Oliveira MRB, Nordi PP, Pires RH, Milori SA, et al. Estudo da prevalência da língua geográfica e fissurada em escolares de Araraquara. Rev Odontol UNESP. 1994;23:339-46.

24. Koay CL, Lim JA, Siar CH. The prevalence of tongue lesions in Malaysian dental outpatients from the Klang Valley area. Oral Dis. 2011;17:210-6.

25. Byrd JA, Bruce AJ, Rogers RS 3rd. Glossitis and other tongue disorders. Dermatol Clin. 2003;21:123-34.

26. Alikhani M, Khalighinejad N, Ghalaiani P, Khaleghi MA, Askari E, Gorsky M. Immunologic and psychologic parameters associated with geographic tongue. Oral Surg Oral Med Oral Pathol Oral Radiol. 2014;118:68-71

27. Gonzaga HF, Chaves MD, Gonzaga LH, Picciani BL, Jorge MA, et al. Environmental factors in benign migratory glossitis and psoriasis: Retrospective study of the association of emotional stress and alcohol and tobacco consumption with benign migratory glossitis and cutaneous psoriasis. J Eur Acad Dermatol Venereol. 2015;29:533-6

28. Bruce AJ, Rogers RS, 3rd. Oral psoriasis. Dermatol Clin. 2003;21:99-104.

29. Daneshpazhooh M, Moslehi H, Akhyani M, Etesami M. Tongue lesions in psoriasis: a controlled study. BMC Dermatol. 2004:4:16.

30. Zargari 0 . The prevalence and significance of fissured tongue and geographical tongue in psoriatic patients. Clin Exp Dermatol. 2006;31:192-5.

31. Costa SC, Hirota SK, Takahashi MD, Andrade H Jr, Migliari DA.. Oral lesions in 166 patients with cutaneous psoriasis: a controlled study. Med Oral Patol Oral Cir
Bucal. 2009;14:e371-5

32. Tomb R, Haji H, Nehme E. Oral lesions in psoriasis. Ann Dermatol Venereol. 2010;137:695-702.

33. Singh S, Nivash S, Mann BK. Matched case-control study to examine association of psoriasis and migratory glossitis in India. Indian J Dermatol Venereol Leprol. 2013;79:59-64.

34. Picciani BLS. Investigação oral em pacientes portadores de psoríase elou língua geográfica: estudo clínico, citopatológico, histopatológico e imunogenético [tese] Niterói (RJ): Universidade Federal Fluminense; 2014. 140 p.

35. Keshavarz E, Roknsharifi S, Shirali Mohammadpour R, Roknsharifi M. Clinical features and severity of psoriasis: A comparison of facial and nonfacial involvement in Iran. Arch Iran Med. 2013;16:25-8.

36. Wang ZH, Zhao YP, Ma XC. Ankylosis of Temporomandibular Joint caused by Psoriatic Arthritis: A Report of Four Cases wit Literature Review. Chin J Dent Res. 2014;17:49-55

37. Gonzaga HFS, Consolaro A. Qual a importância do exame bucal na psoríase? An Bras Dermatol. 1993;135:368-70.

38. De Rosa G, Mignogna C. The histopathology of psoriasis. Reumatismo. 2007:59:46-8

39. Tirumalae R. Psoriasiform dermatoses: Microscopic approach. Indian J Dermatol. 2013;58:290-3.

40. Abe M, Sogabe Y, Syuto T, Ishibuchi H, Yokoyama Y, Ishikawa 0. Successful treatment with cyclosporin administration for persistent benign migratory glossitis. J Dermatol. 2007;34:340-3.

41. Cabrijan L, Lipozencić J, Batinac T, Peternel S, Pastar Z. The role of CD4 and CD8 lymphocytes and macrophages in psoriasis vulgaris. Acta Dermatovenerol Croat. 2009;17:162-5

42. Espelid M, Bang G, Johannessen AC, Leira Jl, Christensen O. Geographic stomatitis: report of 6 cases. J Oral Pathol Med. 1991;20:425-8.

43. Boruah D, Moorchung N, Vasudevan B, Malik A, Chatterjee M. Morphometric study of microvessels, epidermal characteristics and inflammation in psoriasis vulgaris with their correlations. Indian J Dermatol Venereol Leprol. 2013;79:216-23.

44. Vissers WH, Muys L, Erp PE, de Jong EM, van de Kerkhof PC. Immunohistochemica differentiation between inflammatory linear verrucous epidermal nevus (ILVEN) and psoriasis. Eur J Dermatol. 2004;14:216-20.

45. Safia Rana JSZ, Jetley Sujata, Kudesia Madhur. A comparative study of psoriasis and psoriasiform lesion on basis of CD4 and CD8 cell infiltration. Our Dermatol Online. 2012;3:292-7.

46. Cassia FF. Psoríase e artrite psoriásica: estudo das freqüências hla e dos genes kir em uma população miscigenada [tese]. Rio de Janeiro (RJ): Universidade Federal do Rio de Janeiro; 2006. 146 p.

47. Campbell RD, Trowsdale J. Map of the human MHC. Immunol Today. 1993;14:34952.

48. Wysocki GP, Daley TD. Benign migratory glossitis in patients with juvenile diabetes Oral Surg Oral Med Oral Pathol. 1987;63:68-70.

49. Marks R, Taitt B. HLA antigens in geographic tongue. Tissue Antigens. 1980;15:60-2

50. Fenerli A1, Papanicolaou S, Papanicolaou M, Laskaris G. Histocompatibility antigens and geographic tongue. Oral Surg Oral Med Oral Pathol. 1993;76:476-9.

51. Lima Ede A, Lima Mde A. Reviewing concepts in the immunopathogenesis of psoriasis. An Bras Dermatol. 2011;86:1151-8.

52. Valdimarsson H, Karason A, Gudjonsson JE. Psoriasis: a complex clinical and genetic disorder. Curr Rheumatol Rep. 2004:6:314-6.

53. Gudjonsson JE, Karason A, Runarsdottir EH, Antonsdottir AA, Hauksson VB, Jónsson $\mathrm{HH}$, et al. Distinct clinical differences between $\mathrm{HLA}-\mathrm{CW}^{\star} 0602$ positive and negative psoriasis patients--an analysis of 1019 HLA-C- and HLA-B-typed patients. J Invest Dermatol. 2006;126:740-5.

54. Picciani BL, Carneiro S, Sampaio AL, Santos BM, Santos VC, Gonzaga HF, et al. A possible relation of human leucocyte antigens with psoriasis vulgaris and geographic tongue. J Eur Acad Dermatol Venereol. 2015;29:865-74

55. Borrego F, Kabat J, Kim DK, Lieto L, Maasho K, Peña J, et al. Structure and function of major histocompatibility complex (MHC) class I specific receptors expressed on human natural killer (NK) cells. Mol Immunol. 2002;38:637-60.

56. Williams AP, Bateman AR, Khakoo SI. Hanging in the balance. KIR and their role in disease. Mol Interv. 2005;5:226-40.

57. Łuszczek W, Mańczak M, Cisło M, Nockowski P, Wiśniewski A, Jasek M, et al. Gene for the activating natural killer cell receptor, KIR2DS1, is associated with susceptibility to psoriasis vulgaris. Hum Immunol. 2004:65:758-66.

58. Enerbäck C, Martinsson T, Inerot A, Wahlström J, Enlund F, Yhr M, et al. Evidence that HLA-Cw6 determines early onset of psoriasis, obtained using sequencespecific primers (PCR-SSP). Acta Derm Venereol. 1997;77:273-6.

59. Kim TG, Lee HJ, Youn JI, Kim TY, Han H. The association of psoriasis with human 
leukocyte antigens in Korean population and the influence of age of onset and sex. J Invest Dermatol. 2000;114:309-13.

60. Zhang X, Wei S, Yang S, Wang Z, Zhang A, He P, et al. HLA-DQA1 and DQB1 alleles are associated with genetic susceptibility to psoriasis vulgaris in Chinese Han. Int J Dermatol. 2004;43:181-7.

61. Magalhães RF, Biral AC, Pancoto JA, Donadi EA, Mendes CT Jr, Magna LA, et al. Human leukocyte antigen (HLA) and single nucleotide polymorphisms (SNPs) tumor necrosis factor (TNF)-alpha -238 and -308 as genetic markers of susceptibility to psoriasis and severity of the disease in a long-term follow-up Brazilian study. Int J Dermatol. 2010;49:1133-40.

62. Shawkatová I, Javor J, Párnická Z, Kozub P, Zilínková M, Frey P, et al. HLA-C, DRB1 and DQB1 alleles involved in genetic predisposition to psoriasis vulgaris in the Slovak population. Folia Microbiol (Praha). 2013;58:319-24.

63. Guimarães AL, Correia-Silva Jde F, Diniz MG, Xavier GM, Horta MC, Gomez RS. Investigation of functional gene polymorphisms: IL-1B, IL-6 and TNFA in benign migratory glossitis in Brazilian individuals. J Oral Pathol Med. 2007;36:533-7.

\section{MAILING ADDRESS:}

Bruna Lavinas Sayed Picciani

Av. Nossa Senhora de Copacabana, 30 - Apto 406 - Leme 22010-122 - Rio de Janeiro - RJ - Brazil

Email: brunapicciani@yahoo.com.br

How to cite this article: Picciani BLS, Domingos TA, Teixeira-Souza T, Santos VCB, Gonzaga HFS, Cardoso-Oliveira J, Gripp AC, Dias EP, Carneiro S. Geographic tongue and psoriasis: clinical, histopathological, immunohistochemical and genetic correlation - a literature review. An Bras Dermatol. 2016;91(4):410-21. 


\section{Questions}

1. Which another term can be used for geographic tongue?

a) Benign migratory erythema

b) Atrophic glossitis

c) Benign migratory glossitis

d) Cerebriform tongue

2. Several factors are associated with geographic tongue. Which ones?
a) Stress
b) Alcohol
c) Pregnancy
d) All of the above

3. What is another term for the fissured tongue?
a) Geographic tongue
b) Scrotal tongue
c) Cerebriform tongue
d) $\mathrm{B}$ and $\mathrm{C}$ are correct

4. What is the oral condition most often associated with geographic tongue?
a) Glossitis due to nutritional deficiency
b) Fissured tongue
c) Oral candidiasis
d) Bacterial infections

5. Among the clinical variants of psoriasis, which one is most strongly associated with geographic tongue by histopathologic similarities?
a) Vulgaris
b) Palmoplantar
c) Pustular
d) Erythrodermic

6. Which of the following does NOT correspond to one of the microscopic findings of psoriasis?
a) Band-like lymphocytic infiltrate
b) Munro's microabscess
c) Suprapapillary atrophy
d) Parakeratosis

7. What are the cells mainly involved in the pathogenesis of psoriasis?
a) Mast cells
b) T-lymphocytes
c) Langerhans cell
d) Neutrophils

8. Correlate the blanks and mark the correct alternative regarding immunohistochemical findings similar in psoriasis and geographic tongue:
A) Capillaries
( ) Higher expression in the epidermis
B) $\mathrm{Ki}-67$
C) $\mathrm{CD} 4+$
( ) Marked with anti-CD31 antibody
D) $\mathrm{CD} 8+$
( ) Predominantly in the dermis
( ) Nuclear hyperproliferation of cell
a) $\mathrm{B} D \mathrm{AC}$
b) $\mathrm{DACB}$
c) $\mathrm{ACDB}$
d) $\mathrm{CBAD}$

9. What is the prevalence of psoriasis in the world population?
a) $0.6 \%$ to $4.8 \%$
b) $1 \%$ to $3 \%$
c) $5 \%$ to $10 \%$
d) $9.8 \%$ to $18.1 \%$

10. According to Zargari, which was the prevalence of geographic tongue in psoriatic patients?
a) $6 \%$
b) $25 \%$
c) $2 \%$
d) $7,2 \%$

11. Regarding the microscopic aspects, where can Munro's microabscess be located in psoriasis and in geographic tongue?
a) Basal layer of the epithelium
b) Epithelial layer of the cornea
c) Constituting the connective lymphocytic infiltrate
d) Close to areas of vascular ectasia

12. According to Picciani et al, which alleles most strongly demonstrated an association between psoriasis and geographic tongue in the Brazilian population, respectively?
a) HLA-C*06
b) HLA-Bw62 and HLA-Bw63
c) HLA-DR6
d) HLA-B*57 and $-B * 58$

13. What is the link more strongly associated with psoriasis vulgaris?
a) HLA-DR6
b) HLA-B17
c) HLA-C ${ }^{*} 06$
d) HLA-B*27 
14. Which forms of treatment are indicated for geographic tongue?

a) Systemic corticosteroids

b) In the absence of symptoms, drug prescription is not indicated

c) Intralesional injection of immunosuppressive agents

d) Mouthwash with antiseptic solution

\section{Picciani et al considered that GT is strongly associated} with:
a) Late and mild psoriasis
b) Late and severe psoriasis
c) Early and moderate psoriasis
d) Early and severe psoriasis

16. Which of the following HLA alleles are more strongly associated with psoriatic arthritis?
a) $\mathrm{HLA}-\mathrm{C}^{*} 06$
b) HLA-B27
c) HLA-B $* 57$
d) HLA-B17

\section{Check true or false for the following statements:}

( ) In the white area of geographic tongue, it is possible to find atrophy of filiform papillae, which is confirmed by electron microscopy.

( ) The erythematous area presents subepithelial mononuclear cell infiltration, suprapapillary hypertrophy and vascular ectasia.

() The GT lesions in psoriasis and psoriatic patients show no microscopic differences in the white, peripheral and erythematous areas.

( ) The geographic tongue is still considered by some authors as a development change and, therefore, histopathology is not performed generally for diagnostic confirmation.
a) VVFF
b) VFVV
c) FVFV
d) FFFV

18. What were the changes in CD4 + and CD8 + oral lesions found by Picciani et al?

a) They found higher CD8+ levels on the margins of oral lesions of non-psoriatic patients.

b) CD4+ lymphocytes are relevant in the initial phase of oral lesions.

c) The central area of GT showed great increase in CD8+ levels.

d) The study showed increased CD8+ lymphocytes in the peripheral area of lesions in psoriatic patients.
19. Some studies have demonstrated strong correlation between polymorphism of KIR genes and Class I HLA alleles regarding the immune response of killer-cells in psoriasis. What is the correct statement?

a) KIR2DL1 inhibitory gene has a high prevalence in psoriatic patients that present HLA-C ${ }^{*} 04$.

b) KIR2DL1 inhibitory gene may represent a protective factor in psoriatic patients in the regulation of immune response.

c) KIR2DS1 activation gene has a high prevalence in psoriatic patients who have the HLA-C*06 allele.

d) KIR2DL1 activation gene was present in most individuals belonging to psoriasis and control groups.

20. Which factors can explain the low prevalence of HLA-C ${ }^{*} 06$ in the study by Picciani et al?

a) The assessed patients presented were older.

b) Brazilian population has high miscegenation and HLA-C ${ }^{*} 06$ is more frequently found in Caucasian populations.

c) Few patients were analyzed.

d) All of the above are correct.

\begin{tabular}{|c|c|c|c|}
\hline \multicolumn{4}{|c|}{ Answer key } \\
\hline \multicolumn{4}{|c|}{$\begin{array}{l}\text { High frequency ultrasound with color Doppler in Dermatology } \\
\text { 2016;91(3):263-73. }\end{array}$} \\
\hline $1-D$ & $6-A$ & $11-C$ & $16-\mathrm{A}$ \\
\hline $2-B$ & $7-\mathrm{A}$ & $12-C$ & $17-B$ \\
\hline $3-\mathrm{A}$ & $8-D$ & $13-B$ & $18-D$ \\
\hline $4-B$ & $9-B$ & $14-\mathrm{A}$ & $19-C$ \\
\hline $5-D$ & $10-\mathrm{A}$ & $15-\mathrm{D}$ & $20-\mathrm{A}$ \\
\hline
\end{tabular}

\section{Papers}

Information for all members: The EMC-D questionnaire is now available at the homepage of the Brazilian Annals of Dermatology: www.anaisdedermatologia.org.br. The deadline for completing the questionnaire is 30 days from the date of online publication. 